\title{
Intralesional pentostam versus intralesional metronidazole in treating cutaneous leishmaniasis: A comparison study
}

\section{Abstract}

Background and objectives: Cutaneous leishmaniasis can be classified into two different syndromes; New World and Old World. The later is acquired in Asia, Africa, the Middle East, or Europe. This study aimed to compare the effectiveness of intralesional pentostam with intralesional metronidazole in the treatment of cutaneous leishmaniasis.

Methods: An analytical observational study was carried out in the Dermatology Consultancy Department of Erbil Teaching Hospital in Erbil city from April to October 2017. A convenience sampling method was used to recruit 50 study participants who were diagnosed with having cutaneous leishmaniasis. A questionnaire was designed for data collection, and the size with the degree of in duration of the cutaneous lesions was measured. Patients received three injections of either intralesional pentostam or intralesional metronidazole on a two-weekly basis.

Results: The mean \pm SD age of the participants was $32.38 \pm 15.05$ years. Most of the participants were male $(72 \%)$. The mean diameter difference \pm SD after receiving three intralesional injections on a two-weekly basis was $0.7692 \pm 0.62017 \mathrm{~cm}$ for pentostam, compared to $0.4211 \pm 0.62413 \mathrm{~cm}$ for metronidazole $(P=0.070)$. The mean difference in lesion's induration \pm SD was $0.9091 \pm 0.83121$ for pentostam, compared to $0.6875 \pm$ 0.70415 for metronidazole $(P=0.128)$.

Conclusion: Intralesional injection with metronidazole has shown some degree of cure in terms of decrease in the size and induration of the lesions. Although statistically insignificant, intralesional injection of metronidazole was less effective than intralesional injection of pentostam. Further studies are needed with a larger sample size to better understand the effectiveness of metronidazole in the treatment of cutaneous leishmaniasis. Keywords: Cutaneous leishmaniasis; Treatment; Metronidazole; Pentostam; Erbil.

\section{Introduction}

Leishmaniasis is a vector-borne disease caused by flagellated protozoans of the genus Leishmania. ${ }^{1}$ It is a group of diseases with different species of genus Leishmania causing them. The human being is infected through a bite of the sandfly, mainly during the night and outdoors. $^{2}$ It is a major global health problem. Worldwide, about 12 million people are infected, and other 350 million people of about 100 countries are at risk of infection. Annually throughout the world, the incidence of cutaneous leishmaniasis
$(\mathrm{CL})$ and visceral Leishmaniasis $(\mathrm{VL})$ is 0.7-1.2 million and 0.2-.04 million, respectively. ${ }^{3}$ Clinically, leishmaniasis can be presented in three different ways; cutaneous leishmaniasis, visceral leishmaniasis, and mucocutaneous leishmaniasis $(\mathrm{MCL}){ }^{3}$ Cutaneous leishmaniasis can be classified into two different syndromes; New World, if the disease is acquired in the Americas, and Old World, if its acquired in Asia, Africa, the Middle East, or Europe. ${ }^{4}$ Cutaneous leishmaniasis, the most common Leishmanial syndrome worldwide,

${ }^{1}$ Department of Medicine, College of Medicine, Hawler Medical University, Erbil, I raq.

${ }^{2}$ Department of Community Medicine, College of Medicine, Hawler Medical University, Erbil, I raq.

${ }^{3}$ Center for Dermatological Diseases, Directorate of Health, Erbil, I raq.

* Correspondence: sherzad.shabu@hmu.edu.krd 
is responsible for all the cutaneous disease on the Mediterranean littoral west of Greece and some of the disease in North Africa. ${ }^{5}$ In Iraq, CL was endemic in some geographical areas, particularly in Baghdad. After 1980, the disease became widely spread in other parts of the country and reached a state of an epidemic. ${ }^{6}$ After an incubation period ranging from a few weeks to a few months, CL usually causes painless and chronic lesions at the sites infected by sandfly bites. ${ }^{7}$ The $\mathrm{CL}$ lesion starts as erythematous spot before forming a papule, nodule or plague, and this may ulcerate. Untreated cases which may remain several months or even years before healing is completed will leave disfiguring scars, especially on the face. ${ }^{6}$ For diagnosis, the parasite can be demonstrated in histological examinations and through cultures. In Endemic areas where most people have acquired natural immunity following exposure, the skin test is of limited importance. ${ }^{8}$ In general, most of the CL sores heal spontaneously, but in individual cases, the time duration required for these sores to heal cannot be predicted. Trying topical methods of treatment for simple sores is reasonable. The use of systemic pentavalent antimonials (pentostam) could be prescribed for some complicated cases. These cases may include those who do not heal easily as on the lower leg or over joints, those involving mucosa or cartilage and in cases where scarring could be disabling or causing major disfiguring. ${ }^{5}$ Overall, pentostam remains the drug of choice. It inhibits the synthesis of adenosine triphosphate. ${ }^{9}$ For the treatment of $\mathrm{CL}$, some other conventional anti-infective agents were also tried. These included Rifampin with or without Isoniazid, Dapsone, Metronidazole, and Trimethoprim-sulfamethoxazole. ${ }^{4}$ In addition to its direct lethal effect on the parasite causing its death; it is also suggested that metronidazole could interfere with the osmotic pressure locally and harm the microorganism. ${ }^{6}$ Cutaneous leishmaniasis is still considered to be a major health problem in the world, especially in developing countries. Recently, an increase in the incidence of CL was noticeable in Erbil, mainly among military personnel. It is also known that different medications were tried to treat this disease, and none of these has been satisfactory. This study aimed to compare the effectiveness of intralesional pentostam with intralesional metronidazole in the treatment of cutaneous leishmaniasis, and assess the effectiveness of metronidazole as an alternative in the treatment of $\mathrm{CL}$ since health facilities in Erbil have frequently experienced a shortage in the provision of pentostam while metronidazole is widely available.

\section{Methods}

An analytical observational study was carried out in the Dermatology Consultancy Department of Erbil Teaching Hospital in Erbil city, the capital of Iraqi Kurdistan from April to October 2017. A convenience sampling method was used to recruit 50 study participants who were diagnosed with having cutaneous leishmaniasis. All newly diagnosed patients with cutaneous leishmaniasis from both genders and all age groups were included in this study. Patients who were previously diagnosed and started treatment before the onset of this study were excluded. Severely infested patients who had an indication for systemic therapy were also excluded from this study. Diagnosis of cutaneous leishmaniasis was mainly based on clinical presentation, including the history of exposure to insect bite from an endemic area and the presence of nodular indurated or ulcerated lesion with violacious hue in the exposed part of the body. Data collection was done through direct interview using a special questionnaire designed for this purpose. The questionnaire included personal and socio-demographic information such as age, gender, occupation, and residence. It also included measuring the cutaneous lesion size (diameter) and the degree of 
its induration. Before the onset of this study, both pentostam and metronidazole were already used for the treatment of this disease. Patients receiving either intralesional pentostam or intralesional metronidazole were included in this study. The lesion's size (diameter) was measured in centimeter, and its induration was clinically observed based on its severity ranged from plus one up to plus three. Both the lesion's size and its induration were followed up and measured on a two-weekly basis after each intralesional injection up to three injections. Metronidazole $(500 \mathrm{mg} / 100 \mathrm{ml}$ vial) was used. For each cutaneous lesion, $2 \mathrm{ml}$ of metronidazole, which is equivalent to $10 \mathrm{mg}$, was administered intradermally to each lesion until blanching or induration occurs. Pentostam or Sodium Stibogluconate $(200 \mathrm{mg} / 2 \mathrm{ml}$ vial) was used. For each lesion, $0.2-0.8 \mathrm{ml}$ of pentostam was injected intradermally until it produced a complete blanching of the base of the lesion. Ethical approval was obtained from the Research Ethics Committee of the College of
Medicine, Hawler Medical University. Verbally informed consents were obtained from the participants who were assured about the anonymity of the study. The statistical package for the social sciences (version 19) was used for data entry and analysis. A $P$ value of less than 0.05 was considered as statistically significant. The two-independent samples t-test was used to compare the effect of the two drugs on the lesion's size and its induration.

\section{Results}

Of the 50 patients who participated in this study, 36 were males, and 14 were females. Age group 21-40 years constituted $58 \%$ of the participants. The mean \pm SD age of the participants was $32.38 \pm 15.05$ years, with a minimum age of 6 and a maximum of 80 years. The participants were mainly Peshmarga $(44 \%)$ followed by housewives (26\%), government employees $(16 \%)$, and students (14\%). More than half of the participants were based in rural areas around Erbil city, as shown in Table 1.

Table 1: The socio-demographic characteristics of the studied sample.

\begin{tabular}{lccc}
\hline Variable & $\begin{array}{c}\text { Pentostam } \\
\text { No. (\%) }\end{array}$ & $\begin{array}{c}\text { Metronidazole } \\
\text { No. (\%) }\end{array}$ & $\begin{array}{c}\text { Total } \\
\text { No. (\%) }\end{array}$ \\
\hline Age & $7(70)$ & $3(30)$ & $10(100)$ \\
$\leq 20$ & $17(58.6)$ & $12(41.4)$ & $29(100)$ \\
$21-40$ & $6(54.5)$ & $5(45.5)$ & $11(100)$ \\
$\geq 41$ & & & \\
Gender & $19(52.8)$ & $17(47.2)$ & $36(100)$ \\
Male & $11(78.6)$ & $3(21.4)$ & $14(100)$ \\
Female & & & \\
Occupation & $13(59.1)$ & $9(40.9)$ & $22(100)$ \\
Peshmarga & $10(76.9)$ & $3(23.1)$ & $13(100)$ \\
Housewife & $5(62.5)$ & $3(37.5)$ & $7(100)$ \\
Government employee & $2(28.6)$ & $5(71.4)$ & \\
Student & & & $23(100)$ \\
Address & $12(52.2)$ & $11(47.8)$ & $27(100)$ \\
Urban & $18(66.7)$ & $9(33.3)$ & $50(100)$ \\
Rural & $30(60)$ & $20(40)$ & \\
Total & & & \\
\hline
\end{tabular}


Of 50 study participants, 23 (46\%) had the lesion on the upper extremities, 17 (34\%) on the lower extremities, $8(16 \%)$ on the face and neck and 2 (4\%) on the trunk. Regarding the number of lesions that the patients had, $24(48 \%)$ were with only one lesion, $22(44 \%)$ had 2-4 lesions, and only four patients $(8 \%)$ had five and more lesions. Half of the participants had the lesions for 5-12 weeks, 17 (34\%) for four and fewer weeks and only $8(16 \%)$ for thirteen and more weeks, as shown in Table 2. Regarding the treatment type, 30 $(60 \%)$ patients were receiving intralesional pentostam injections, while 20 (40\%) patients were receiving intralesional metronidazole injections. The study revealed that the mean diameter difference $\pm \mathrm{SD}$ after receiving three intralesional injections on the two-weekly basis was $0.7692 \pm 0.62017 \mathrm{~cm}$ for pentostam, compared to $0.4211 \pm 0.62413 \mathrm{~cm}$ for metronidazole and this was statistically insignificant. The mean difference in lesion's induration \pm SD after receiving three intralesional injections on the two-weekly basis was $0.9091 \pm 0.83121$ for pentostam, compared to $0.6875 \pm 0.70415$ for metronidazole which was statistically insignificant, as shown in Table 3.

Table 2: The lesion characteristics of the studied sample.

\begin{tabular}{lccc}
\hline Variable & $\begin{array}{c}\text { Pentostam } \\
\text { No. (\%) }\end{array}$ & $\begin{array}{c}\text { Metronidazole } \\
\text { No. (\%) }\end{array}$ & $\begin{array}{c}\text { Total } \\
\text { No. (\%) }\end{array}$ \\
\hline Site of the lesion & & & \\
Face \& neck & $6(75)$ & $2(25)$ & $8(100)$ \\
Trunk & $1(50)$ & $1(50)$ & $2(100)$ \\
Upper extremities & $14(60.9)$ & $9(39.1)$ & $23(100)$ \\
Lower extremities & $9(52.9)$ & $8(47.1)$ & $17(100)$ \\
Number of lesions & & & \\
One & $17(70.8)$ & $7(29.2)$ & $24(100)$ \\
$2-4$ & $12(54.5)$ & $10(45.5)$ & $22(100)$ \\
$\geq 5$ & $1(25)$ & $3(75)$ & $4(100)$ \\
Duration of lesion (weeks) & & & \\
$\leq 4$ & $10(58.8)$ & $7(41.2)$ & $17(100)$ \\
$5-12$ & $15(60)$ & $10(40)$ & $25(100)$ \\
$\geq 13$ & $5(62.5)$ & $3(37.5)$ & $8(100)$ \\
Total & $30(60)$ & $20(40)$ & $50(100)$ \\
\hline
\end{tabular}

Table 3: Association between type of the drug and the mean difference in lesion's size and its induration*

\begin{tabular}{|c|c|c|c|c|c|}
\hline \multirow{2}{*}{ Lesion difference } & \multicolumn{2}{|c|}{$\begin{array}{l}\text { Pentostam } \\
(\text { No }=26)\end{array}$} & \multicolumn{2}{|c|}{$\begin{array}{l}\text { Metronidazole } \\
\quad(\text { No = 19) }\end{array}$} & \multirow[t]{2}{*}{$P$ value } \\
\hline & Mean & SD & Mean & SD & \\
\hline Size difference & 0.7692 & \pm 0.62017 & 0.4211 & \pm 0.62413 & 0.070 \\
\hline Induration difference & 1.0385 & \pm 0.66216 & 0.7222 & \pm 0.66211 & 0.128 \\
\hline
\end{tabular}

* There was loss to follow up of 5 cases ( 4 cases receiving pentostam and 1 case metronidazole). 


\section{Discussion}

For the treatment of $\mathrm{CL}$, pentostam are considered to be the most common and effective medications used. Sometimes, the use of such group of drugs is associated with a range of problems like resistance to the drug, toxicity, increased failure rate, and prolonged therapy course. In addition, some patients suffered some sorts of cardiac or renal insufficiency as side effects of these drug compounds. However, pentostam remains the first drug of choice or treatment of leishmaniasis in its different forms. ${ }^{10}$ In the early 1980s, some reports about un-treated patients with these drugs were announced, but unfortunately, there is still no development in the production of novel antileishmanial drug. ${ }^{11}$ Out of 50 patients enrolled in this study, males constituted $72 \%$ and females $28 \%$ of the total sample. The male proportion was also higher $(58.3 \%)$ compared to female $(41.7 \%)$ in a study conducted in Ahvaz city, South of Iran. ${ }^{12}$ While in a study conducted in Babylon Governorate of Iraq in 2004, males constituted only $45.7 \%$ of the sample compared to $54.3 \%$ females. ${ }^{6}$ Male involvement at a higher rate than female might be attributed to the fact that males are more involved in outdoor social activities, and they cover their body with a cloth to a less extent compared to females. This justification might also explain the fact that $44 \%$ of our sample were Peshmarga from different military bases. Housewives constituted $26 \%$ of the sample, $16 \%$ different governmental jobs, and $14 \%$ students. While in a study conducted in Iran between 2011-2013, housewives constituted $20.7 \%$ of the sample compared to $17.1 \%$ students, $15.7 \%$ children, $7.2 \%$ workers, and $3.2 \%$ farmers. ${ }^{14}$ The mean age \pm standard deviation of our sample was $32.38 \pm 15.05$, with a minimum and maximum ages of six and eighty years respectively, while the mean age of patients enrolled in Ahvaz study was 28.8 years, with a minimum and maximum ages of fifteen and forty years respectively. ${ }^{12}$ The majority $(58 \%)$ of the sample age was between 21-40 years old compared to $45 \%$ of the sample age between 11-30 years in a study conducted in Southwest Iran. ${ }^{13}$ More than half of our sample $(54 \%)$ were of rural origin compared to $46 \%$ of urban origin, while in the Southwest Iran study, only $44.3 \%$ were of rural origin compared to $55.7 \%$ of urban origin. ${ }^{13}$ In this study, upper extremities were involved in $46 \%$ of the patients compared to $34 \%$ for lower extremities, $16 \%$ for the face and neck, and only $4 \%$ for the trunk. These results came close to those of the study conducted in Southwest Iran which reported $45.7 \%$ involvement of hands, $27.4 \%$ of feet, $19.1 \%$ of face and $7.8 \%$ of other places of the body. ${ }^{13}$ With regard to the number of lesions, our study revealed that $48 \%$ of the patients have only a single lesion, compared to $44 \%$ with $2-4$ lesions and the remaining $8 \%$ with equal or more than five lesions. The proportion of patients presented with a single lesion was much higher $(71 \%)$ in a study conducted in the Eastern part of Suadi Arabia ${ }^{15}$ and another study conducted in Ta'if region of the country $(81 \%) .{ }^{16}$ Although statistically insignificant, the study revealed a better improvement, both in terms of the lesion's size and induration, with the use of intralesional pentostam compared to intralesional metronidazole after receiving three intralesional injections of 2-week intervals. These results come somehow consistent with those of a study conducted in Ahvaz city of Iran, in 2002, to compare the effectiveness of intralesional injection of metronidazole with meglumine antimoniate which revealed an $81 \%$ recovery rate after receiving eight injections of meglumine antimoniate compared to only $16.6 \%$ recovery rate with metronidazole. ${ }^{12}$ Another study conducted in Anuradhapura in Sri Lanka on the efficacy of intralesional metronidazole versus intralesional sodium stibogluconate (SSG) in cutaneous leishmaniasis showed that $39.6 \%$ of patients received SSG and $14.8 \%$ of those received metronidazole had achieved a complete response after 
12 weeks. A further increase in the complete cure rate was reported to $66.03 \%$ and $29.78 \%$ of patients after 24 weeks of treatment, respectively. This difference in the cure rate was statistically significant. ${ }^{17}$ While a study conducted in Hilla city, Babylon Governorate of Iraq, in 2004 to assess the effectiveness of intralesional metronidazole in the treatment of cutaneous leishmaniasis revealed a significant high cure rate $(75 \%)$ of cutaneous leishmaniasis's lesions with local infiltration of $1 \%$ metronidazole. ${ }^{6}$ Since few patients were presented with ulceration at the start of the study, we were not able to take ulceration into consideration as a factor for the follow up in responding to the treatment administered. Concerning patients who had more than one lesion, and in order to prevent confusion, only the biggest lesion was considered for the follow up. The time required for scar formation is variable, and it may take several months. Because of the limited duration of the study, scar formation was not considered in the follow up of cases.

\section{Conclusion}

Intralesional injection with metronidazole has shown some degree of cure in terms of decrease in the size and induration of the lesions. Although statistically insignificant, the study revealed that intralesional injection of metronidazole is not as effective as intralesional injection of pentostam in the treatment of cutaneous leishmaniasis. Further studies need to be planned with a bigger sample size to better analyze the effectiveness of metronidazole in the treatment of cutaneous leishmaniasis.

\section{Competing interests}

The authors declare that they have no competing interests.

\section{References}

1. WHO. Leishmaniasis. Fact sheet, April 2017. (Accessed on November 20, 2017, at http:// www.who.int/mediacentre/factsheets/fs375/en/).
2. Downing C, Tyring S. Parasitic diseases. In: Griffiths C, Barker J, Blelker T, Chalmers R, Creamer D editors. Rook's Textbook of Dermatology. $9^{\text {th }}$ ed. UK: John Wiley \& Sons, Ltd; 2016. P. 1058-69.

3. Alvar J, Velez ID, Bern C, Herrero M, Desjeux P, Cano $\mathrm{J}$ et al. Leishmaniasis worldwide and global estimates of its incidence. PLoS One 2012; 7(5):e35671.

4. Lee SA, Hasbun R. Therapy of cutaneous leishmaniasis. Int J Infect Dis 2003; 7:86-93.

5. Malek JM, Ghosn SH. Leishmaniasis and other protozoan infections. In: Goldsmith LA, Katz SI, Gilchrest BA, Paller AS, Leffell DJ, Wolff K editors. Fitzpatrick's Dermatology in General Medicine. $8^{\text {th }}$ ed. United States: The McGraw-Hill Companies; 2012. P. 2527-37.

6. Al-Hassnawi HH, Al-Saeed MS, Al-Yassari HF, Al -Qaysi SI. The use of intralesional metronidazole in the treatment of cutaneous leishmaniasis. Med J Babylon 2006; 3(4):260-4.

7. Aronson N, Herwaldt BL, Libman M, Pearson R, Lopez-Velez R, Weina $P$, et al. Guidelines diagnosis and treatment of leishmaniasis: Clinical practice guidelines by the Infectious Diseases Society of America (IDSA) and the American Society of Tropical Medicine and Hygiene (ASTMH). Am J Trop Med Hyg 2017; 96(1):2445.

8. Faber WR, Oskam L, VanGool T, Kroon NC, Knegt-Junk KJ, Hofwegen $\mathrm{H}$, et al. Value of diagnostic techniques for cutaneous leishmaniasis. J AM Acad Dermatol 2003; 49:704.

9. Markle WH, Makhoul K. Cutaneous leishmaniasis: Recognition and treatment. Am Fam Physician 2004; 69(6):1455-60.

10. Mendonça-Filho RR, Rodrigues IA, Alviano DS, Santos AL, Soares RM, Alviano CS, et al. Leishmanicidal activity of poly-phenolic-rich extract from husk fiber of Co-cos nucifera Linn (Palmae). Res Microbiol 2004; 155(3):13643.

11. Salman MT, Khan RA, Shukla I. Antibac-terial Activity of Nigella sativa Linn. Seed oil against multi-drug resistant bacteria from clinical isolates. Nat Prod Radiance 2008; 7(1):10-4.

12. Mapar MA, Omidian M. Intralesional injections of metronidazole versus meglumineantimoniate for the treatment of cutaneous leishmaniasis. Jundishapur J Microbiol 2010; 3(2):79-83.

13. Khademvatan S, Salmanzadeh S, Foroutan-Rad M, Bigdeli S, Hedayati-Rad F, Saki J, et al. Spatial distribution and epidemiological features of cutaneous leishmaniasis in Southwest of Iran. Alexandria J Med 2017; 53:93-8.

14. Norouzinezhad F, Ghaffari F, Norouzinejad A, Kaveh F, Gouya MM. Cutaneous leishmaniasis in Iran: Results from an epidemiological study in urban and rural provinces. Asian Pac J Trop Biomed 2016; 6(7):614-9. 
15. Al-Tawfiq JA, Abukhamsin A. Cutaneous leishmaniasis: A 46-year study of the epidemiology and clinical features in Saudi Arabia (1956-2002). Int J Infect Dis 2004; 8:24450.

16. Khan W, Zakai HA. Epidemiology, pathology and treatment of cutaneous leishmaniasis in Ta'if region of Saudi Arabia. Iran J Parasitol 2014; 9:365-73.

17. Kellapatha IP, Wijesinghe WAMS, Ranatunga RAWC, Athapathu W, Bandara MRCK, Sumanasena JAMB, et al. Randomized double blind study on efficacy of intralesional metronidazole versus intralesional sodium stibogluconate in cutaneous leishmaniasis. AMJ 2015; 9(2 Supp):S03 